\title{
REVIEW
}

\section{A Scoping Review of the Pharmacy Curriculum Outcomes Assessment Literature}

\author{
Nicholas R. Nelson, PharmD, ${ }^{a}$ Sarah M. Anderson, PharmD, ${ }^{a}$ Jacqueline M. Zeeman, PharmD, ${ }^{\text {a,b }}$ Denise H. \\ Rhoney, PharmD ${ }^{\mathrm{a}}$ \\ ${ }^{\text {a }}$ University of North Carolina at Chapel Hill, UNC Eshelman School of Pharmacy, Chapel Hill, North Carolina \\ ${ }^{\mathrm{b}}$ University of North Carolina at Chapel Hill, UNC Eshelman School of Pharmacy, Chapel Hill, North Carolina
}

Corresponding Author: Denise H. Rhoney, University of North Carolina at Chapel Hill, UNC Eshelman School of Pharmacy, 328 Beard Hall, Campus Box 7574, Chapel Hill, NC 27599-7574. Email: $\underline{\text { drhoney@ unc.edu }}$

Submitted December 9, 2020; accepted March 18, 2021; ePublished April 2021

Objective. To identify themes, gaps, and sources of evidence from the literature to inform practice and additional areas for research in pharmacy education with respect to the Pharmacy Curriculum Outcomes Assessment (PCOA). Findings. Nineteen articles have been published describing the administration and use of PCOA. Since PCOA was made a curricular requirement by the Accreditation Council of Pharmacy Education in 2016, the focus of PCOA related literature has shifted from administration practices (4 vs 2, respectively) to determining models that may predict student performance on the assessment ( $2 \mathrm{vs} 5$, respectively) or how the examination might be used to predict future performance ( 1 vs 7, respectively), especially on the North American Pharmacist Licensing Examination. While there has been growing literature recently focused on the PCOA's utility for measuring performance, few variables have been consistently used.

Summary. This review found no studies whose objectives aligned with the initial intended use of the PCOA defined by National Association of Boards of Pharmacy including tracking individual student performance throughout the curriculum, benchmarking programs against other programs, and evaluating if a program is meeting their desired outcomes. Additionally, there is no consensus across the Academy as to the proper use of the PCOA and a paucity of literature of how the PCOA informs schools/colleges of the effectiveness of their curriculum. There is a need for the Academy to establish a uniform application for PCOA, assess resources required of programs for this required assessment, and its utility to measure curricular effectiveness and/or student performance.

Keywords: Pharmacy Curriculum Outcomes Assessment (PCOA), assessment, evaluation, curricular improvement, curriculum effectiveness

\section{INTRODUCTION}

The Pharmacy Curriculum Outcomes Assessment (PCOA) is an assessment tool developed by the National Associations of Boards of Pharmacy (NABP) as an external measure of student performance in Doctor of Pharmacy (PharmD) curricula. ${ }^{1}$ First introduced in 2008 as an optional assessment for schools/colleges of pharmacy to administer to students, administration of PCOA to all students nearing completion of the didactic curriculum became an accreditation requirement in the Accreditation Council for Pharmacy Education (ACPE) Standards 2016. ${ }^{2}$ According to NABP, the PCOA can be used to track individual student performance throughout the curriculum, benchmark programs against other programs, and evaluate if a program is meeting their desired outcomes. ${ }^{1}$

The 2020-2021 PCOA includes 225 items, with 200 contributing to a student's total score, from five question formats: multiple-choice, multiple-response, constructed-response, ordered-response, and hot-spot. ${ }^{1,3}$ The assessment spans four content areas and 28 subtopic areas determined from a 2015 survey of PharmD outcomes. ${ }^{4}$ The content areas are mapped to Appendix 1 of the Center for the Advancement of Pharmacy Education Educational Outcomes ${ }^{5}$ and include: Basic Biomedical Sciences (BBS) (10\% of assessment), Pharmaceutical Sciences (PS) (33\% of assessment), Social/Behavioral/Administrative Sciences (SBAS) (22\% of assessment), and Clinical Sciences (CS) (35\% of assessment). ${ }^{6}$

Multiple studies of the PCOA have been published since its inception, however, they are far-ranging and contain varied approaches. Despite the information given from NABP, ACPE, and published literature, there is ongoing discussion regarding the use, applicability, and administration of the PCOA. Additionally, Mok and Romalelli highlighted the need for further research to advance out understanding of the utility of the PCOA related to student core knowledge. ${ }^{7}$ The purpose of this scoping review was to identify the extent, range, and quantity of evidence regarding the use of PCOA and identify potential gaps which could lead to this future research. 


\section{METHODS}

This scoping review sought to determine what has been published regarding the PCOA. The five-phase procedure outlined by Arksey and O'Malley was utilized: 1) Identify the research question; 2) Identify relevant studies; 3) Select relevant articles; 4) Chart the data; and 5) Collate, summarize, and report the results. ${ }^{8}$ A research team of coinvestigators with experience in pharmacy education and scoping reviews was established for this review.

This scoping review focused on addressing "What has been published regarding the Pharmacy Curriculum Outcomes Assessment?" This research question was purposefully broad to holistically incorporate the extent, range, and nature of literature regarding the PCOA. The initial search was conducted on 18 November 2019 using PubMed, Embase, and Scopus for literature published since January 2008. The search query consisted of terms including "Pharmacy Curriculum Outcomes Assessment" or "PCOA" within the title or abstract. Specific pharmacy education journals (eg, American Journal of Pharmacy Education, Currents in Pharmacy Teaching and Learning) and references from included articles were searched manually on 9 March 2020 to ensure the thoroughness of the search and up to date coverage.

All articles identified by the search strategy were imported into Covidence (Veritas Health Innovation, Melbourne, Australia) after removing duplicates. Articles then underwent a two-stage screening process consisting of title/abstract review and full-text review for inclusion conducted by two authors. Letters to the editor, response papers, and conference abstracts were excluded along with articles that did not evaluate PCOA as the main objective. Articles that did not have an abstract were included for full-text review if the title indicated inclusion. All conflicts were resolved independently by the remaining authors.

Each author participated in data extraction using a spreadsheet created to chart data in Microsoft Excel Version 16.41 (Microsoft, Redmond, Washington), which included the following categories: author, year of publication, institution type, sample size, response rate, single or multicenter study, stakes associated with PCOA and level of stakes, predictors used for assessing PCOA, objective of study/article, methodology of study/analysis, outcomes/results of study/article, remediation program associated with PCOA administration, and "other." Other was included given the heterogeneity of article types included in the analysis. Once data were charted in the spreadsheet, the authors met to discuss key themes that were identified.

\section{RESULTS}

The database and manual searches yielded 75 articles with 27 included for screening after removing duplicates. In total, 23 articles met full-text screening criteria and 19 articles were included for analysis. The four articles that were excluded from analysis included one conference abstract, one letter to the editor, one meta-analysis, and one review. Four key themes were identified including: administration and use of PCOA,${ }^{9-13}$ resource investment in PCOA, ${ }^{14}$ student predictors of performance on PCOA, ${ }^{15-21}$ and PCOA as a predictor of future performance ${ }^{18,21-27}$ Comparing these themes before and after Standards 2016, recent publications have focused primarily on predictors of PCOA performance and PCOA as a predictor of future performance. (Figure 1)

Administration and Use of Pharmacy Curriculum Outcomes Assessment. Since the implementation of the PCOA in 2008 and requirement in 2016, schools and colleges have been trying to find the best use of the assessment. Table 1 shows the common areas that have been reviewed by three major surveys evaluating PCOA administration between 20142017. Common areas of interest included: years administered, reasons for administration, utilization of results, stakes associated with PCOA, who reviewed the results, and remediation plans. These findings indicate that the PCOA is mostly administered in the P3 year without high stakes. ${ }^{9-11}$ How PCOA results are utilized in the assessment plan, who reviews PCOA results and when, as well as remediation plans vary across institutions. (Table 1)

More specifically, two studies with different objectives used the PCOA exam to highlight gaps in learning for either the student or an elective course for a view into curricular effectiveness. ${ }^{12,13}$ In a study that was conducted prior to the PCOA administration requirement, Naughton and Friesner sought to determine if a correlation existed between thirdyear students' perceived knowledge and actual knowledge assessed by PCOA. ${ }^{12}$ BBS was the only content area where there was a significant correlation between actual and perceived knowledge. In the other domains, students overestimated their knowledge leading the investigators to suggest having a standardized measure to assess curricular effectiveness outside student perceptions may be beneficial. ${ }^{12}$ Burris and colleagues, however, assessed the impact of an elective journal club course on longitudinal curriculum performance using PCOA performance along with grades in other key CS courses and acute/ambulatory care APPEs. Overall scaled scores on PCOA were on average 24.5 points higher and clinical science section scaled score were 28.2 points higher in students who participated in the elective. ${ }^{13}$

Resources invested in Pharmacy Curriculum Outcomes Assessment. Only one study explored the financial and faculty resources used to prepare students for PCOA examination. ${ }^{14}$ This study also surveyed programs on the investment in NAPLEX preparation and compared how investments to prepare students for both exams compares to the NAPLEX pass rates. A total of $91 \%$ of colleges/schools of pharmacy responded to the survey with only $20 \%(\mathrm{n}=18)$ providing 
PCOA preparation to the students compared to $79 \%(\mathrm{n}=72)$ providing NAPLEX review. The type of PCOA review programs ranged from live review sessions by faculty $(n=5)$ to providing question banks developed by a vendor $(n=4)$ or internally developed question banks $(n=3)$. The majority of respondents $(n=9)$ do not spend extra monetary dollars on their programs while five colleges/schools spent $\$ 1-\$ 4,999$ and one spent $\$ 30,000-\$ 34,999$. The vast majority of schools providing this preparation are legacy schools founded prior to $1995(\mathrm{n}=12 / 18)$ with an even distribution between public $(\mathrm{n}=10)$ and private $(\mathrm{n}=8)$ programs. Notably programs that did not provide PCOA preparation cited that they had an interest in gaining insight in estimates of student knowledge. ${ }^{14}$

Predictors of Pharmacy Curriculum Outcomes Assessment performance. Seven articles evaluated various demographics, admissions, and academic factors as predictors of PCOA performance all at single institutions ${ }^{15-21}$ Four articles assessed PCOA taken only during the third professional year, ${ }^{18-21}$ while one article reviewed PCOA performance for 142 P2 PCOA test takers. ${ }^{16}$ Two studies evaluated PCOA over multiple professional years, P1-P3. ${ }^{15,17}$ Additionally, three studies assessed predictors of PCOA content areas in addition to total scaled score. ${ }^{18-20}$

Five articles evaluated pre-pharmacy factors to predict student performance on PCOA. ${ }^{16-20}$ (Table 2) All five studies included cumulative pre-pharmacy GPA as a predictor of PCOA total scaled score performance, however, only Hein et al. and Medina et al. found similarly significantly positive correlations between the two. Pre-pharmacy science GPA was found to be a positive predictor of PCOA total scaled score in the three studies that assessed it, although this trend did not continue for all four PCOA content areas. ${ }^{18-20}$ All five studies also assessed Pharmacy College Admission Test (PCAT) performance as a predictor of PCOA performance, however, Giuliano et al. only reported PCAT sub-score results. Medina et al., however, determined the inclusion of three PCAT sub-scores (Verbal, Biology, Chemistry) collectively explained more variance than PCAT composite alone, and thus did not include PCAT composite in their models. ${ }^{20}$

Three studies included unique admissions criteria to their study that were found to significantly predict PCOA performance. ${ }^{16,17,20}$ Of particular interest, only Medina and colleagues included race/ethnicity in their model to predict PCOA performance, determining that non-white students are likely to score lower on the PCOA total, PS, SBAS, and CS than white students $(\mathrm{r}=-0.26[-0.39--0.12])$. PCAT attempts was also found to have a negative relationship with PCOA total and BBS scaled scores $\left(\mathrm{r}=-0.28[-0.41-0.14) .{ }^{20}\right.$ Gillette and colleagues found their use of the Health Science Reasoning Test consistently predicted PCOA performance across first, second, and third program years (standardized $\beta=0.33[0.10], 0.329[0.109], 0.401$ [0.148], respectively), yet determined earning a bachelor's degree prior to entering pharmacy school had no difference on PCOA performance in any program year across the 301 students over the 4 years they evaluated (all p>0.05) ${ }^{17}$ Finally, Giuliano et al. determined P1 GPA was a stronger predictor of PCOA performance for students who competed pre-requisites at a different institution than their pharmacy school compared to those who remained at the same university (26.6/GPA point vs 53.37/GPA point minus 96.94 , respectively). ${ }^{16}$

Seven studies evaluated academic factors for association of PCOA performance. (Table 3) All studies found significant positive correlations between cumulative pre-PCOA grade point average (GPA) and PCOA total scaled scores, although of varying degrees. ${ }^{15-21}$ Hein et al. found students' pre-PCOA GPA to account for the most variance in their model (26\% of $60 \%$ total variance predicted by model). ${ }^{18}$ Interestingly, Scott et al. evaluated P3 PCOA scores over three years, finding the correlation strength of pre-PCOA GPA decreased as students progressed through the curriculum. ${ }^{15}$ Garavalia and colleagues assessed GPA on all required courses within the program as the only academic factor associated with PCOA and determined it to have a large effect size. ${ }^{21}$ Only two articles assessed student remediation as a predictor of PCOA performance, however, yielding somewhat conflicting results. ${ }^{19,20}$ In a post hoc analysis, McDonough and colleagues found a negative relationship for students who had poor academic performance and did not repeat any academic content compared to those with no academic performance issues. Students with poor performance who repeated academic content, however, performed no differently than those who had no academic issues. ${ }^{19}$ Conversely, Medina et al. found that remediation of any course was negatively correlated with PCOA total scaled score. ${ }^{20}$ Giuliano et al. was the only article that noted a remediation plan associated with student PCOA performance, where students who score $\geq$ two standard deviations below the institution's average must undergo a remediation plan with a faculty advisor. ${ }^{16}$ Medina and colleagues also evaluated an institution specific curricular element in their study, finding that a PCOA Prep test taken the semester before the official PCOA had a significant positive correlation with PCOA total scaled score as well as each content area score $\left(\mathrm{R}^{2}=0.09,0.2,0.41,0.17,0.28\right.$, respectively $)$, explaining the most unique variance in their model $(9 \%$ of $61 \%) .{ }^{20}$

\section{Pharmacy Curriculum Outcomes Assessment as predictor of future performance. One study evaluated 23} different predictive covariates, including PCOA score on measuring pre-advanced pharmacy practice experience (APPE) readiness in 226 graduating students form the years 2015-2018. ${ }^{22}$ Pre-APPE readiness was defined as midpoint core APPE rotation scores, which they applied in three different statistical models. In all three models, PCOA total scaled score was a significant predictor of APPE scores/readiness. In the All Core APPE Rotation model, PCOA total scaled score, pre- 
APPE GPA, and age were the strongest predictors $\left(\mathrm{R}^{2}=0.16\right)$. In the Acute and Ambulatory Care Model, the only predictor was PCOA total scaled score $\left(\mathrm{R}^{2}=0.07\right)$. While in the Number of Midpoint Core Clerkship Failing Scores Model, the strongest predictors were PCOA total scaled score, age, final GPA in therapeutic course sequence and problems in pharmacotherapy final grade. ${ }^{22}$ Additionally, Hein and colleagues concluded that PCOA PS and CS content areas were also useful for students to leverage APPEs to fill gaps in content/application knowledge. ${ }^{18}$

Seven articles evaluated PCOA as a predictor of licensing examination, with five evaluating NAPLEX ${ }^{18,21,23-26}$ and one evaluating MPJE. ${ }^{27}$ Five studies were conducted at single institutions and yielded similar results, finding that third professional year (P3) PCOA total scaled scores were positively correlated with NAPLEX scores. ${ }^{18,21,23-25}$ (Table 4) Specifically, Naughton and Friesner evaluated 108 P3 PCOA test takers in 2009-2010 and found that PCOA total scaled score and content area scaled scores were significantly correlated with all NAPLEX scores, including total NAPLEX and the three NAPLEX competency area scores, except PCOA SBAS scores and NAPLEX Competency Area 2: Assess Safe and Accurate Methods to Prepare and Dispense Medications. ${ }^{23}$ Similarly, Shah et al. and Hein et al. evaluated 433 P3 PCOA test takers from 2012-2016 and 384 P3 PCOA test takers from 2012-2015, respectively, and their subsequent NAPLEX scores. ${ }^{18,24}$ Hein et al found that PCOA total scaled score and all subtopic domain scales scores were positively correlated with NAPLEX overall scores. ${ }^{18,24}$ Furthermore, Shah et al. determined P3 PCOA scaled scores $<349$ was found to be one independent factor associated with a poor NAPLEX outcome, defined as NAPLEX overall score $\leq 82 .{ }^{23}$ Similarly, Welch and Karpen found PCOA to be a significant predictor of both NAPLEX scores and NAPLEX pass rates. ${ }^{25}$ Garavalia et al. found that PCOA scores accounted for $8 \%$ of variance on NAPLEX scores, although GPA explained $14 \%$ of NAPLEX score variance. ${ }^{21}$

The positive correlation between PCOA and NAPLEX scores at these single institutions was also observed in one multi-institution study evaluating 1,454 P3 PCOA test takers in 2012-2014 and their subsequent NAPLEX scores at 6 colleges/schools of pharmacy. PCOA total scaled scores and NAPLEX overall scores were significantly correlated as were PCOA total and content area scaled scores and NAPLEX overall and competency area scores. Linear regression models estimated a 1-point increase in PCOA total score was associated with a 0.15-point increase in NAPLEX overall score when controlling for other factors. ${ }^{26}$

In addition to evaluating the utility of the PCOA to predict NAPLEX scores, one study evaluated the relationship between PCOA and Multistate Pharmacy Jurisprudence Examination (MPJE). In this single center study evaluating the North Carolina (NC) MPJE, Mospan and colleagues sought to determine an association between PCOA total and content area scaled scores in addition to several admissions and curriculum variables and MPJE scores. ${ }^{27}$ (Table 4)

\section{DISCUSSION}

The literature regarding the PCOA has increased since it was made an accreditation requirement by ACPE in 2016. Further, the themes of these publications have shifted (Figure 1). Most publications prior to the accreditation requirement focused on how colleges/schools of pharmacy were administering the assessment and if faculty could predict student PCOA performance. Since its requirement, however, more attention has been paid toward predicting student performance on PCOA and using the PCOA as a way to predict future student performance, particularly on licensure examinations. Interestingly, although not an intended use of the examination, ${ }^{1}$ PCOA performance has been commonly used to predict North American Pharmacist Licensure Examination (NAPLEX) scores and pass rates although the blueprints for these examinations are different. ${ }^{6,26}$ Additionally, if the primary use of the PCOA is to predict future success on the NAPLEX, it might be more beneficial to administer the NAPLEX to students prior to graduation instead of creating another exam given the differing blueprints for each assessment.

One study was published with respect to the resources required for programs to implement the PCOA. ${ }^{14}$ This 2017 study found wide variability among financial and faculty resources colleges/schools allocated toward preparing for and administering the PCOA. Notably, this survey was administered in January 2016 and included information before the PCOA became an accreditation requirement. A follow-up survey to gain insight into the resources required to conduct the PCOA and how colleges/schools of pharmacy are utilizing the results may be helpful to investigate the cost effectiveness of administering the assessment, especially given the number of programs administering the PCOA has nearly tripled since the first survey. ${ }^{28}$ A clear use for the examination that is broadly accepted among the Academy, whether that is the initial intent of student tracking, program benchmarking, and curriculum outcome evaluation, or the recently described use as a predictor of future success, should be established first to justify the resources devoted to administering the assessment. If the latter, however, the Academy and NABP should critically evaluate if this is the appropriate assessment for that purpose considering the varied blueprints between PCOA and the licensure exams (ie, NAPLEX, MPJE).

Similarities were found among the studies which evaluated various admission and curriculum predictors of PCOA performance. PCAT Composite score and undergraduate science GPA were positive predictors in all studies which evaluated these variables, while sex seemed to be a nonsignificant predictor. It is important to note, however, that not all 
studies evaluated a common set of admissions variables and several institution specific variables were included in the respective studies, making direct comparison difficult. Investigating pre-PCOA GPA, Daugherty and Malcom confirmed a correlation between P3 GPA and PCOA performance, although a high degree of heterogeneity was seen in most models. ${ }^{29}$ The use of GPA as a predictor poses some potential challenges, however. First, using pre-PCOA GPA does not allow much time to work with at-risk students given that students take the examination anywhere from 1-5 months after this GPA is calculated. Furthermore, there has been movement within the Academy toward competency-based education with the implementation of entrustable professional activities. ${ }^{30}$ As more colleges/schools consider and adopt competencybased curricula, traditional GPA may no longer be able to be calculated, limiting the degree to which GPA is representative of the curriculum.

Course remediation may be a more applicable variable, but has showed mixed results, possibly due to inconsistencies in how remediation is defined across the Academy. Of note, McDonough and colleagues found that students who met remediation criteria but did not repeat the course scored significantly lower on the PCOA total scaled score as well as the PS and CS content areas. ${ }^{19}$ This could be because of the greater focus of the PCOA on these areas (33\% and $35 \%$, respectively). While the specific course or course content was not described, identification of students struggling with this content during the course and early remediation could improve student PCOA scores. Additionally, multiple studies reported a correlation between PCOA total scaled score and NAPLEX score, which was also found by Daugherty and Malcom in their meta-analysis, indicating course remediation may improve NAPLEX scores. ${ }^{29}$

There are some limitations to this review. First, there is a possibility that this review may have missed some relevant studies. To minimize this risk, however, multiple databases were searched as well as specific American pharmacy education journals. Another notable limitation to this review is lack of critical appraisal of included articles. However, the purpose of this scoping review was to summarize the current literature and not evaluate the quality of the data which allowed for a greater range of studies and methodologies to be included and gaps be identified from possibly low-quality research. This was especially important given that the PCOA has been an accreditation requirement for less than five years and a myriad of study designs and objectives could have been utilized throughout the literature.

This scoping review has identified few uses of PCOA that are in line with NABP's initial intent of the exam, including tracking individual student performance throughout the curriculum, benchmarking programs against other programs, and evaluating if a program is meeting their desired outcomes. The majority of colleges/schools of pharmacy do not administer the assessment over multiple years ${ }^{9}$ and are therefore not able to track individual student performance throughout the curriculum. Further, only one study discussed comparing colleges/schools of pharmacy PCOA performances, which was published six years before the PCOA requirement was implemented in $2016 .{ }^{15}$ Only one included study described how a program may utilize the PCOA to evaluate their desired outcomes, ${ }^{13}$ although $76 \%$ of respondents noted using PCOA for curricular assessment. ${ }^{10}$ Medina and colleagues, however, propose that the intent of PCOA may be to assess for APPE readiness instead of curricular effectiveness, ${ }^{20}$ which complements the study by Nyman et al., showing PCOA score was a modest but consistent predictor of APPE performance. ${ }^{22}$ Nevertheless, because PCOA is a content/knowledge based examination, caution should be used in using it as the sole assessment of APPE readiness. APPEs should prepare students for pharmacy practice which requires academic and non-academic competencies, including knowledge and skills necessary of a pharmacist, of which the PCOA only measures knowledge. Therefore, the results from Nyman and colleagues might indicate suboptimal assessments for APPEs are being utilized if knowledge is such a heavy predictor of student performance and critical skills are not adequately represented.

\section{CONCLUSION}

Based on the published literature of the PCOA, there seems to be inconsistencies in how colleges/schools of pharmacy are utilizing the examination. Furthermore, these uses do not seem to be in line with the initial intent of the PCOA set forth by NABP. If a main purpose of the PCOA is to give insight into the effectiveness of a program's curriculum, more studies like Burris and colleagues are warranted to investigate this linkage. Additionally, future studies using the PCOA to identify areas for curricular improvement may shed light on the value and utility of the assessment. This, in addition to a more recent study on the resources, both financial and human, is needed to better understand the investment pharmacy programs take to administer the PCOA and its utility to measure curricular effectiveness. 


\section{REFERENCES}

1. National Association of Boards of Pharmacy. PCOA. Accessed March 2, 2021.

https://nabp.pharmacy/programs/pcoa/

2. Accreditation Council for Pharmacy Education. Accreditation Standards and Key Elements for the Professional Program in Pharmacy Leading to the Doctor of Pharmacy Degree. Published 2015. Accessed March 2, 2021. https://www.acpe-accredit.org//pdf/Standards2016FINAL.pdf

3. National Association of Boards of Pharmacy. Sample items of the pharmacy curriculum outcomes assessment ${ }^{\circledR}$ (PCOA®). Published 2019. Accessed March 2, 2021. https://nabp.pharmacy/wp-content/uploads/2016/07/PCOASample-Items.pdf

4. National Association of Boards of Pharmacy. The 2015 United States Schools and Colleges of Pharmacy Curricular Survey - Summary Report.; 2016. https://nabp.pharmacy/wp-content/uploads/2016/09/2015-USPharmacy-Curricular-Survey-Summary-Report.pdf

5. Medina M, Plaza C, Stowe C, et al. Center for the Advancement of Pharmacy Education 2013 educational outcomes. Am J Pharm Educ. 2013;77(8):162.

6. National Association of Boards of Pharmacy. Content Areas of the Pharmacy Curriculum Outcomes Assessment ${ }^{\circledR}$ (PCOA®). Published 2016. Accessed March 2, 2021. https://nabp.pharmacy/wp-content/uploads/2016/07/PCOAContent-Areas-2016.pdf

7. Mok TY, Romanelli F. Identifying best practices for and utilities of the pharmacy curriculum outcome assessment examination. Am J Pharm Educ. 2016;80(10). doi:10.5688/ajpe8010163

8. Arksey H, O’Malley L. Scoping studies: Towards a methodological framework. Int J Soc Res Methodol Theory Pract. 2005;8(1):19-32. doi:10.1080/1364557032000119616

9. Gortney JS, Bray BS, Salinitri FD. Implementation and use of the pharmacy curriculum outcomes assessment at US schools of pharmacy. Am J Pharm Educ. 2015;79(9). doi:10.5688/ajpe799137

10. Gortney JS, Rudolph MJ, Augustine JM, et al. National trends in the adoption of PCOA for student assessment and remediation. Am J Pharm Educ. 2019;83(6):Article 6796. doi:10.5688/ajpe6796

11. Sweet B V, Assemi M, Boyce E, et al. Characterization of use of the pharmacy curriculum outcomes assessment across accredited colleges of pharmacy. Am J Pharm Educ. 2019;83(7):7091. doi:10.5688/ajpe7091

12. Naughton CA, Friesner DL. Comparison of pharmacy students' perceived and actual knowledge using the pharmacy curricular outcomes assessment. Am J Pharm Educ. 2012;76(4). doi:10.5688/ajpe76463

13. Burris JN, Frederick EK, Malcom DR, et al. Impact of a journal club elevtice course on student learning measures. Am J Pharm Educ. 2019;83(7):6827.

14. Lebovitz L, Shuford VP, DiVall M V, et al. Creating an arms race? Examining school costs and motivations for providing NAPLEX and PCOA preparation. Am J Pharm Educ. 2017;81(7). doi:10.5688/ajpe8175909

15. Scott DM, Bennett LL, Ferrill MJ, et al. Pharmacy Curriculum Outcomes Assessment for Individual Student Assessment and Curricular Evaluation. Am J Pharm Educ. 2010;74(10):183. doi:10.5688/aj7410183

16. Giuliano CA, Gortney J, Binienda J. Predictors of performance on the pharmacy curriculum outcomes assessment (PCOA). Curr Pharm Teach Learn. 2016;8(2):148-154. doi:10.1016/j.cptl.2015.09.011

17. Gillette C, Rudolph M, Rockich-Winston N, et al. Predictors of student performance on the Pharmacy Curriculum Outcomes Assessment at a new school of pharmacy using admissions and demographic data. Curr Pharm Teach Learn. 2017;9:84-89. doi:10.1016/j.cptl.2016.08.033

18. Hein B, Messinger NJ, Penm J, et al. Correlation of the pharmacy curriculum outcomes assessment and selected pre-pharmacy and pharmacy performance variables. Am J Pharm Educ. 2019;83(3):342-346. doi:10.5688/ajpe6579

19. McDonough SL, Spivey CA, Chisholm-Burns MA, et al. Examination of factors relating to student performance on the pharmacy curriculum outcomes assessment. Am J Pharm Educ. 2019;83(2):205-211. doi:10.5688/ajpe6516

20. Medina MS, Neely S, Draugalis JLR. Predicting pharmacy curriculum outcomes assessment performance using admissions, curricular, demographics, and preparation data. Am J Pharm Educ. 2019;83(10):7526. doi:10.5688/ajpe7526

21. Garavalia LS, Prabhu S, Chung E, et al. An analysis of the use of Pharmacy Curriculum Outcomes Assessment (PCOA) scores within one professional program. Curr Pharm Teach Learn. 2017;9(2):178-184. doi:10.1016/j.cptl.2016.11.008

22. Nyman H, Moorman K, Tak C, et al. Advanced pharmacy practice experiences - A modeling exercise to identify predictors of student readiness. Am J Pharm Educ. 2019;84(5):7783. doi:10.5688/ajpe7233

23. Naughton CA, Friesner DL. Correlation of P3 PCOA scores with future NAPLEX scores. Curr Pharm Teach Learn. 2014;6(6):877-883. doi:10.1016/j.cpt1.2014.07.017 
24. Shah S, Peng I, Seifert CF. A model to predict NAPLEX outcomes and identify students needing additional preparation. Curr Pharm Teach Learn. 2019;11(8):810-817. doi:10.1016/j.cptl.2019.04.009

25. Welch AC, Karpen SC. Comparing student performance on the old vs new versions of the NAPLEX. Am J Pharm Educ. 2018;82(3):224-226. doi:10.5688/ajpe6408

26. Rudolph MJ, Gortney JS, Maerten-Rivera JL, et al. A study of the relationship between the PCOA and NAPLEX using a multi-institutional sample. Am J Pharm Educ. 2019;83(2):153-160. doi:10.5688/ajpe6867

27. Mospan G, Gillette C, Mospan CM. Predictors of performance on the North Carolina Multistate Pharmacy Jurisprudence Examination. Curr Pharm Teach Learn. 2020;12(1):35-40. doi:https://doi.org/10.1016/j.cpt1.2019.10.004

28. American Association of Colleges of Pharmacy. Academic Pharmacy's Vital Statistics. Published 2020. Accessed March 2, 2021. https://www.aacp.org/article/academic-pharmacys-vital-statistics\#: :text=Institutions and Programs,Education (ACPE) accredits programs.

29. Daugherty KK, Malcom DR. Assessing the relationship among PCOA performance, didactic academic performance, and NAPLEX scores. Am J Pharm Educ. 2020;(ePub ahead of print). doi:10.5688/ajpe7233

30. Pittenger AL, Chapman SA, Frail CK, et al. Entrustable professional activities for pharmacy practice. Am J Pharm Educ. 2016;80(4). doi:10.5688/ajpe80457 
Figure 1: Key Themes in Published Pharmacy Curriculum Outcomes Assessment (PCOA) Literature

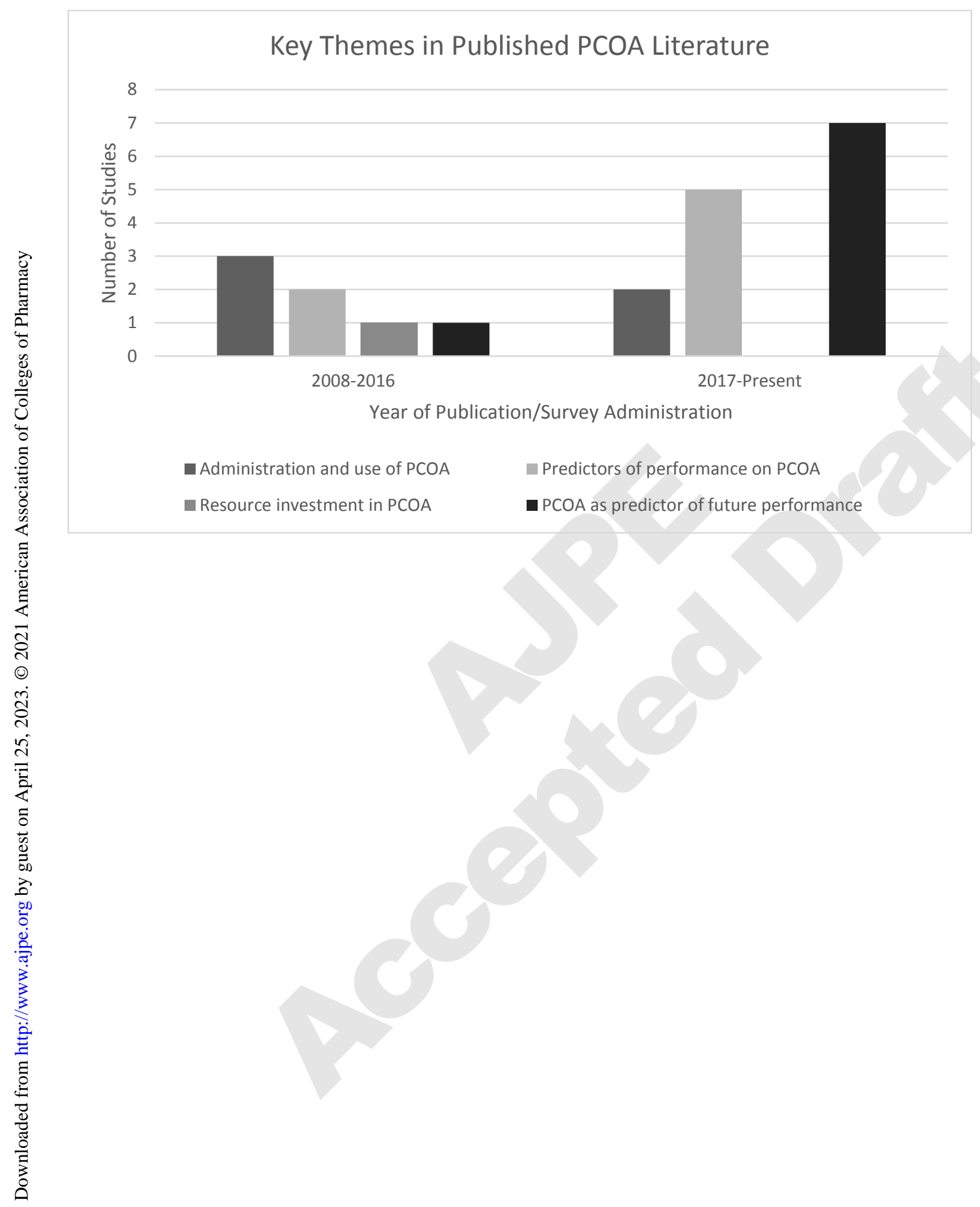




\begin{tabular}{|c|c|c|c|c|c|c|c|}
\hline $\begin{array}{l}\text { Author / Year of } \\
\text { Survey } \\
\text { Administration }\end{array}$ & $\begin{array}{l}\text { Response } \\
\text { Rate - n } \\
\quad(\%) \\
\text { Public/ } \\
\text { Private }\end{array}$ & $\begin{array}{c}\text { Programmatic Year(s) } \\
\text { of PCOA administration } \\
- \\
n(\%)\end{array}$ & $\begin{array}{c}\text { Reasons for } \\
\text { administration - } \\
\mathbf{n}(\%)\end{array}$ & $\begin{array}{c}\text { Utilization of Results } \\
\text { in Assessment Plan - } \\
\text { n (\%) }\end{array}$ & $\begin{array}{c}\text { Stakes }-\mathbf{n} \\
(\%)\end{array}$ & $\begin{array}{c}\text { Reviewer prior to } \\
\text { student } \\
\text { distribution - } \\
\text { n }(\%)\end{array}$ & $\begin{array}{c}\text { Remediation plans }-\mathbf{n} \\
(\%)\end{array}$ \\
\hline $\begin{array}{l}\text { Gortney } \\
2014\end{array}$ & $\begin{array}{l}41 / 52 \\
(79 \%) \\
22(54 \%) / \\
19(46 \%)\end{array}$ & $\begin{array}{l}\text { P1: } 10(26 \%) \\
\text { P2: } 11(29 \%) \\
\text { P3: } 35(92 \%) \\
\text { P4: } 3(8 \%)\end{array}$ & $\begin{array}{l}\text { Programmatic } \\
\text { assessment: } 29 \\
(76 \%) \\
\text { Benchmarking: } 28 \\
(74 \%) \\
\text { ACPE National } \\
\text { Assessment: } 25 \\
\text { (66\%) } \\
\text { Individual } \\
\text { feedback: } 25 \\
(66 \%) \\
\text { Feasibility: } 22 \\
(58 \%)\end{array}$ & $\begin{array}{l}\text { Summative } \\
\text { examination: } 13(34 \%) \\
\text { Internal assessment } \\
\text { alternate years in } \\
\text { curriculum: } 8(21 \%) \\
\text { Combination of PCOA } \\
\text { and clinical skills- } \\
\text { based assessment: } 11 \\
(29 \%)\end{array}$ & $\begin{array}{l}\text { None: } 23 \\
(61 \%) \\
\text { Low: } 10 \\
(26 \%) \\
\text { Medium: } 3 \\
\text { (8\%) } \\
\text { High: } 1 \\
\text { (3\%) }\end{array}$ & $\begin{array}{l}\text { Administrator }{ }^{\mathrm{a}}: 32 \\
(84 \%) \\
\text { Committee }^{\mathrm{b}}: 16 \\
(38 \%) \\
\text { Faculty advisors: } 8 \\
(21 \%) \\
\text { Department chair: } \\
1(3 \%)\end{array}$ & $\begin{array}{l}\text { Not in use: } 25(66 \%) \\
\text { Required when } \\
\text { threshold not met: } 4 \\
(11 \%) \\
\text { Other: } 4(11 \%)\end{array}$ \\
\hline $\begin{array}{l}\text { Gortney }{ }^{10} \\
2016\end{array}$ & $\begin{array}{l}92 / 135 \\
(68 \%)^{c}\end{array}$ & $\begin{array}{l}\text { P1: } 13(14 \%) \\
\text { P2: } 15(16 \%) \\
\text { P3: } 85(92 \%) \\
\text { P4: } 5(5 \%) \\
\text { Number of years of } \\
\text { PCOA Administration } \\
\text { across curriculum: } \\
1 \text { year: } 72(78 \%) \\
2 \text { years: } 13(14 \%) \\
3 \text { years: } 7(7 \%) \\
4 \text { years: } 1(1 \%)\end{array}$ & & $\begin{array}{l}\text { Curricular assessment: } \\
70(76 \%) \\
\text { Individual student } \\
\text { performance } \\
\text { assessment: } 68(74 \%) \\
\text { Cohort performance } \\
\text { assessment: } 65(71 \%) \\
\text { Student progress } \\
\text { assessment: } 18(20 \%) \\
\text { Other: } 14(15 \%)\end{array}$ & $\begin{array}{l}\text { None/Low: } \\
\text { P1: NR } \\
(50 \%) \\
\text { P2: NR } \\
(47 \%) \\
\text { P3: NR } \\
(75 \%) \\
\text { Medium: } \\
\text { P1: NR } \\
\text { (50\%) } \\
\text { P2: NR } \\
(53 \%) \\
\text { P3: NR } \\
\text { (17\%) } \\
\text { High: } \\
\text { P3:NR } \\
\text { (2\%) } \\
\text { Other: } \\
\text { P3: NR } \\
\text { (6\%) }\end{array}$ & $\begin{array}{l}\text { At risk identified } \\
\text { by: } \\
\text { Committee }{ }^{\text {b. }} 9 \\
(45 \%) \\
\text { Dean or director of } \\
\text { assessment: } 7 \\
(35 \%) \\
\text { Remediation } \\
\text { identified by: } \\
\text { Faculty committee: } \\
5(25 \%) \\
\text { Dean or director of } \\
\text { assessment: } 11 \\
(55 \%)\end{array}$ & $\begin{array}{l}\text { Poor performers } \\
\text { required remediation: } \\
\text { 25\% } \\
\text { P3: } 20(24 \%) \\
\text { P2: } 7(47 \%) \\
\text { P1: } 6(54 \%)\end{array}$ \\
\hline $\begin{array}{l}\text { Sweet }^{11} \\
2017\end{array}$ & $\begin{array}{l}126 / 139 \\
(91 \%) \\
64(51 \%) / \\
62(49 \%)\end{array}$ & $\begin{array}{l}\text { P3 only prior to Standards } \\
\text { 2016: } 29(52 \%)\end{array}$ & $\begin{array}{l}\text { Identify at-risk } \\
\text { students: } 37(29 \%)\end{array}$ & $\begin{array}{l}\text { Provided individual } \\
\text { scores to students: } 122 \\
(97 \%)\end{array}$ & NA & NA & $\begin{array}{l}\text { Poor performers } \\
\text { required to meet with } \\
\text { advisor/ administrator: } \\
37(29 \%)\end{array}$ \\
\hline
\end{tabular}


Note: Only 56 programs

administered PCOA prior

to the 2016 requirement
Provided class/cohort

scores to students: 76

(60\%)

Changes to didactic

curriculum: 35 (81\%)
All students required to meet with advisor: 14

(11\%)

Remediation: 15 (35\%)

Student progression: 9

(21\%)

${ }^{\mathrm{a}}$ Dean, associate dean, assistant dean

${ }^{\mathrm{b}}$ Progressions or assessment

${ }^{\mathrm{c}}$ Did not report public vs private institutions

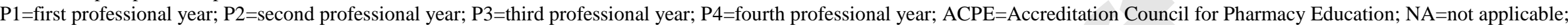
$\mathrm{NR}=$ not reported 
Table 2. Admission Criteria as Predictors of Pharmacy Curriculum Outcomes Assessment (PCOA) Performance

\begin{tabular}{|c|c|c|c|c|c|c|c|c|c|c|}
\hline \multirow{3}{*}{$\begin{array}{c}\text { PCOA } \\
\text { Area }\end{array}$} & \multirow{3}{*}{$\begin{array}{c}\text { Reference }(\mathbf{n}) / \\
\text { Professional Year PCOA } \\
\text { Administered }\end{array}$} & \multirow{3}{*}{$\begin{array}{c}\text { Male } \\
\text { Gender }\end{array}$} & \multicolumn{7}{|c|}{ Correlation Results (r) } & \multirow[b]{3}{*}{ Quantitative } \\
\hline & & & \multicolumn{2}{|c|}{ Undergraduate GPA } & \multicolumn{5}{|c|}{ PCAT } & \\
\hline & & & Cumulative & Science & Composite & Verbal & Reading & Biology & Chemistry & \\
\hline \multirow[t]{8}{*}{ Total } & Giuliano $^{16}(142) /$ P2 & NA & NS & NA & NA & NS & 0.389 & NS & NS & NS \\
\hline & Gillette $^{17} /$ & & & & & & & & & \\
\hline & P1 (293) & NS & NS & NA & 0.416 & NA & NA & NA & NA & NA \\
\hline & P2 (214) & NS & NS & NA & 0.465 & NA & NA & NA & NA & NA \\
\hline & P3 (133) & NS & NS & NA & 0.292 & NA & NA & NA & NA & NA \\
\hline & $\operatorname{Hein}^{18}(384) /$ P3 & NA & 0.24 & 0.25 & 0.6 & NA & NA & NA & NA & NA \\
\hline & McDonough $^{19}$ (159) / P3 & 0.47 & NS & 0.21 & 0.53 & 0.47 & 0.47 & 0.4 & 0.33 & 0.3 \\
\hline & Medina $^{20}$ (179) / P3 & NS & 0.24 & 0.29 & 0.51 & 0.46 & 0.28 & 0.36 & 0.3 & NS \\
\hline \multirow[t]{3}{*}{ BBS } & $\operatorname{Hein}^{18}(384) /$ P3 & NA & 0.19 & 0.21 & 0.46 & NA & NA & NA & NA & NA \\
\hline & McDonough $^{19}$ (159) / P3 & 0.36 & NS & NS & 0.32 & 0.29 & 0.18 & 0.35 & 0.26 & NS \\
\hline & $\operatorname{Medina}^{20}(179)$ / P3 & 0.14 & NS & NA & NA & NS & NA & 0.17 & NS & NS \\
\hline \multirow[t]{3}{*}{ PS } & $\operatorname{Hein}^{18}(384) /$ P3 & NA & 0.23 & 0.28 & 0.5 & NA & NA & NA & NA & NA \\
\hline & McDonough $^{19}$ (159) / P3 & 0.47 & NS & 0.2 & 0.42 & 0.38 & 0.29 & 0.32 & 0.32 & 0.26 \\
\hline & Medina $^{20}(179)$ / P3 & NS & NS & NA & NA & 0.2 & NA & 0.2 & 0.02 & NS \\
\hline \multirow[t]{3}{*}{ SBAS } & $\operatorname{Hein}^{18}(384)$ / P3 & NA & 0.14 & NS & 0.42 & NA & NA & NA & NA & NA \\
\hline & McDonough $^{19}$ (159) / P3 & NS & NS & NS & 0.51 & 0.54 & 0.53 & 0.32 & 0.17 & 0.27 \\
\hline & Medina $^{20}(179)$ / P3 & NS & 0.01 & NA & NA & 0.24 & NA & NS & NS & NS \\
\hline \multirow[t]{3}{*}{$\mathrm{CS}$} & $\operatorname{Hein}^{18}(384)$ / P3 & NA & 0.18 & 0.14 & 0.46 & NA & NA & NA & NA & NA \\
\hline & McDonough $^{19}$ (159) / P3 & 0.42 & NS & 0.2 & 0.4 & 0.33 & 0.31 & 0.31 & 0.28 & 0.26 \\
\hline & Medina $^{20}(179)$ / P3 & NS & NS & NA & NA & 0.2 & NA & 0.1 & NS & 0.1 \\
\hline
\end{tabular}

GPA=grade point average; PCAT=Pharmacy College Admissions Test; P1=first professional year; P2=second professional year; P3=third professional year; NA=not applicable; NS=not significant; BBS=Basic Biomedical Sciences; PS=Pharmaceutical Sciences; SBAS=Social/Behavioral/Administrative Sciences; CS=Clinical Sciences; all p<0.05 
Table 3. Pharmacy Curriculum Criteria as Predictors of Pharmacy Curriculum Outcomes Assessment (PCOA) Performance

\begin{tabular}{|c|c|c|c|}
\hline \multirow[b]{2}{*}{ PCOA Area } & \multirow[b]{2}{*}{$\begin{array}{l}\text { Reference / Professional Year } \\
\text { PCOA Administered (n) }\end{array}$} & \multicolumn{2}{|r|}{ Correlation Results (r) } \\
\hline & & $\begin{array}{l}\text { Pre-PCOA } \\
\text { GPA }\end{array}$ & Course remediation \\
\hline \multirow[t]{20}{*}{ Total } & Scott et al. ${ }^{15} /$ & & \\
\hline & P1 (NR) & 2008: 0.4 & NA \\
\hline & & 2009: NS & NA \\
\hline & & 2010: NS & NA \\
\hline & P2 (NR) & 2008: 0.32 & NA \\
\hline & & 2009: NS & NA \\
\hline & & 2010: 0.15 & NA \\
\hline & P3 (NR) & 2008: 0.71 & NA \\
\hline & & 2009: 0.46 & NA \\
\hline & & 2010: 0.26 & NA \\
\hline & Giuliano et al. ${ }^{16}$ / P2 (142) & $26.597 *$ & NA \\
\hline & Garavalia et al. ${ }^{21}$ / P3 (271) & 0.47 & NA \\
\hline & Gillette et al. ${ }^{17} /$ & & \\
\hline & P1 (293) & 0.218 & NA \\
\hline & P2 (214) & 0.299 & NA \\
\hline & P3 (133) & 0.439 & NA \\
\hline & Hein et al. ${ }^{18}$ / P3 (384) & 0.6 & NA \\
\hline & McDonough et al. ${ }^{19}$ / P3 (159) & & $\begin{array}{c}\text { No need:Progressed }{ }^{\text {a }} \text { - significant, NR } \\
\text { No Need:Remediated }{ }^{\mathrm{b}} \text { - NS }\end{array}$ \\
\hline & & 0.5 & Progressed:Remediated ${ }^{\mathrm{c}}$ - NS \\
\hline & Medina et al. ${ }^{20} /$ P3 (179) & 0.57 & -0.19 \\
\hline \multirow[t]{3}{*}{ BBS } & Hein et al. ${ }^{18} /$ P3 (384) & 0.47 & NA \\
\hline & McDonough et al. ${ }^{19}$ / P3 (159) & 0.19 & $\begin{array}{c}\text { No need:Progressed }{ }^{\mathrm{a}} \text { - NS } \\
\text { No Need:Remediated }{ }^{\mathrm{b}} \text { - NS } \\
\text { Progressed:Remediated }{ }^{\mathrm{c}} \text { - NS }\end{array}$ \\
\hline & Medina et al. ${ }^{20} / \mathrm{P} 3$ (179) & 0.14 & 0.1 \\
\hline \multirow[t]{3}{*}{ PS } & Hein et al. ${ }^{18}$ / P3 (384) & 0.51 & NA \\
\hline & McDonough et al. ${ }^{19}$ / P3 (159) & 0.42 & $\begin{array}{c}\text { No need:Progressed }{ }^{\mathrm{a}} \text { - significant, NR } \\
\text { No Need:Remediated } \text { - NS } \\
\text { Progressed:Remediated }{ }^{\mathrm{c}} \text { - NS }\end{array}$ \\
\hline & Medina et al. ${ }^{20} / \mathrm{P} 3$ (179) & NS & NS \\
\hline \multirow[t]{3}{*}{ SBAS } & Hein et al. ${ }^{18}$ / P3 (384) & 0.31 & NA \\
\hline & McDonough et al. ${ }^{19}$ / P3 (159) & 0.24 & $\begin{array}{c}\text { No need:Progressed }{ }^{\mathrm{a}}-\mathrm{NS} \\
\text { No Need:Remediated }{ }^{\mathrm{b}} \text { - NS } \\
\text { Progressed:Remediated }{ }^{\mathrm{c}} \text { - NS }\end{array}$ \\
\hline & Medina et al. ${ }^{20} /$ P3 (179) & 0.1 & NS \\
\hline \multirow[t]{3}{*}{ CS } & Hein et al. ${ }^{18}$ / P3 (384) & 0.53 & NA \\
\hline & McDonough et al. ${ }^{19}$ / P3 (159) & 0.56 & $\begin{array}{c}\text { No need:Progressed }{ }^{\mathrm{a}} \text { - significant, NR } \\
\text { No Need:Remediated }{ }^{\mathrm{b}} \text { - NS } \\
\text { Progressed:Remediated }{ }^{\mathrm{c}} \text { - NS }\end{array}$ \\
\hline & Medina et al. ${ }^{20} /$ P3 (179) & 0.1 & NS \\
\hline
\end{tabular}

*Unstandardized Beta coefficient

${ }^{\text {a }}$ No need for remediation vs. Need for remediation but progressed without remediation

${ }^{\mathrm{b}}$ No need for remediation vs. Need for remediation and remediated

${ }^{\mathrm{c}}$ Need for remediation but progressed without remediation vs Need for remediation and remediated

$\mathrm{GPA}=$ grade point average; $\mathrm{NR}=$ not reported; $\mathrm{P} 1=$ first professional year; $\mathrm{P} 2=$ second professional year; $\mathrm{P} 3=$ third professional year; NA=not applicable; NS=not significant; BBS=Basic Biomedical Sciences; PS=Pharmaceutical Sciences; SBAS=Social/Behavioral/Administrative Sciences; CS=Clinical Sciences; all $\mathrm{p}<0.05$

Table 4. Pharmacy Curriculum Outcomes Assessment (PCOA) as a predictor for licensure examination performance 


\section{Reference / Professional Year} PCOA Administered (n)

NAPLEX Total

NAPLEX Area 1

NAPLEX Area 2

NAPLEX Area 3

NAPLEX pass rate NC MPJE
Naughton and Friesner ${ }^{23}$ / P3 (108)

Garavalia et al. ${ }^{21}$ / P3 (271)

Welch and Karpen ${ }^{25}$ / P3 (201)

Hein et al. ${ }^{18}$ / P3 (384)

Rudolph et al. ${ }^{26}$ / P3 (1454)

Naughton and Friesner ${ }^{23}$ / P3 (108)

Rudolph et al. ${ }^{26}$ / P3 (1460)

Naughton and Friesner ${ }^{23}$ / P3 (108)

Rudolph et al. ${ }^{26} / \mathrm{P} 3$ (1460)

Naughton and Friesner ${ }^{23}$ / P3 (108)

Rudolph et al. ${ }^{26}$ / P3 (1460)

Welch and Karpen ${ }^{25}$ / P3 (201) Mospan et al. ${ }^{27} /$ NR (85)

\section{Total BBS}

$0.338 \quad 0.571$

0.59

0.44

0.57

NA NA

0.13* NA NA NA NA

0.64

0.42

0.59

$0.32 \quad 0.58$

0.54

0.37

0.51

$0.32 \quad 0.5$

0.583

0.43

0.532

0.363

0.584

0.47

0.44

0.25

0.44

0.351

0.25

$\begin{array}{lll}0.399 & \text { NS } & 0.322\end{array}$

0.46

0.27

0.45

0.33

0.39

0.464

0.446

$0.419 \quad 0.298$

0.397

$0.34 \quad 0.22$

0.29

$0.22 \bigcirc 0.33$

$0.028 *$

NA

NA

NA

NA

0.28

NS

NS

0.28

NS

Beta coefficient

P3 =third Professional Year; BBS=Basic Biomedical Sciences; PS=Pharmaceutical Sciences;

SBAS=Social/Behavioral/Administrative Sciences; $C S=$ Clinical Sciences; NAPLEX=North American Pharmacist Licensure Examination; NA=not applicable; NS=not significant; NC MPJE=North Carolina Multistate Pharmacy Jurisprudence Examination; NR=not reported; all $\mathrm{p}<0.05$ 